\title{
Fibromyalgia Assessment Screening Tool: Clues to Fibromyalgia on a Multidimensional Health Assessment Questionnaire for Routine Care
}

\author{
Kathryn A. Gibson (iD), Isabel Castrejon (iD, Joseph Descallar (iD), and Theodore Pincus (iD)
}

\begin{abstract}
Objective. To develop feasible indices as clues to comorbid fibromyalgia (FM) in routine care of patients with various rheumatic diseases based only on self-report multidimensional Health Assessment Questionnaire (MDHAQ) scores, which are informative in all rheumatic diagnoses studied.

Methods. All patients with all diagnoses complete an MDHAQ at each visit; the 2011 FM criteria questionnaire was added to the standard MDHAQ between February 2013 and August 2016. The proportion of patients who met $2011 \mathrm{FM}$ criteria or had a clinical diagnosis of FM was calculated. Individual candidate MDHAQ measures were compared to 2011 FM criteria using receiver-operating characteristic (ROC) curves; cutpoints to recognize FM were selected from the area under the curve (AUC) for optimal tradeoff between sensitivity and specificity. Cumulative indices of 3 or 4 MDHAQ measures were analyzed as fibromyalgia assessment screening tools (FAST).

Results. In 148 patients, the highest AUC in ROC analyses versus 2011 FM criteria were seen for MDHAQ symptom checklist, self-report painful joint count, pain visual analog scale (VAS), and fatigue VAS. The optimal cutpoints were $\geq 16 / 60$ for symptom checklist, $\geq 16 / 48$ for self-report painful joint count, and $\geq 6 / 10$ for both pain and fatigue VAS. Cumulative FAST indices of $2 / 3$ or $3 / 4$ MDHAQ measures correctly classified $89.4-91.7 \%$ of patients who met 2011 FM criteria.

Conclusion. FAST3 and FAST4 cumulative indices from only MDHAQ scores correctly identify most patients who meet 2011 FM criteria. FAST indices can assist clinicians in routine care as clues to FM with a general rheumatology rather than FM-specific questionnaire. (First Release January 15 2020; J Rheumatol 2020;47:761-9; doi:10.3899/jrheum.190277)
\end{abstract}

Key Indexing Terms:

FIBROMYALGIA ASSESSMENT SCREENING TOOLS

FIBROMYALGIA MULTIDIMENSIONAL HEALTH ASSESSMENT QUESTIONNAIRE

Fibromyalgia (FM) is a common disorder in the general population $^{1}$, with a considerably higher prevalence in people with rheumatic diseases ${ }^{2,3,4,5}$. As with most rheumatic

From the Department of Rheumatology, Liverpool Hospital, Liverpool, Sydney, New South Wales, Australia; University of New South Wales, Sydney, Australia; Division of Rheumatology, Department of Internal Medicine, Rush University Medical Center, Chicago, Illinois, USA; Ingham Institute for Applied Medical Research, Liverpool, Sydney, New South Wales, Australia.

Dr. Pincus holds a copyright and trademark on MDHAQ and RAPID3 (Routine Assessment of Patient Index Data 3), for which he receives royalties and license fees, all of which are used to support further development of quantitative questionnaire measurements for patients and doctors in clinical rheumatology care.

K.A. Gibson, MD, PhD, Department of Rheumatology, Liverpool Hospital, and University of New South Wales; I. Castrejon, MD, PhD, Division of Rheumatology, Department of Internal Medicine, Rush University Medical Center; J. Descallar, BSc, Mbiostat, University of New South Wales, and Ingham Institute for Applied Medical Research; T. Pincus, MD, Division of Rheumatology, Department of Internal Medicine, Rush University Medical Center.

Address correspondence to Dr. K.A. Gibson, Liverpool Hospital, Rheumatology, Locked Bag 7103, Liverpool BC, Liverpool, New South Wales 1871, Australia.E-mail: Kathy.gibson@health.nsw.gov.au Accepted for publication August 6, 2019. diseases, no gold standard diagnostic marker is available for FM. In an effort to standardize the identification of FM, the American College of Rheumatology (ACR) developed FM classification criteria in $1990^{6}$, based on the clinical information of 558 consecutive patients, 293 with FM according to experts in FM versus 265 controls. The combination of widespread pain and $>11$ over 18 tender points identified on physical examination yields a sensitivity of $88 \%$ and specificity of $81 \%$. These criteria were modified in 2010 , with no tender point examination, but rather a patient questionnaire for widespread body pain and symptom severity as well as physician ratings, and designated as "preliminary diagnostic criteria" rather than classification criteria ${ }^{7}$. A further modification was introduced in 2011, based entirely on the patient self-report widespread pain index and symptom severity scale questionnaire, without any requirement for physician assessment, and was designed for "epidemiologic and clinical studies" but not intended for diagnosis of $\mathrm{FM}^{8}$.

FM criteria are not used in most routine clinical care, other than by subspecialists. It is not feasible to ask patients with different diagnoses to complete different patient self-report questionnaires in busy clinical settings. As a consequence,

Personal non-commercial use only. The Journal of Rheumatology Copyright @ 2020 . All rights reserved. 
clinicians may both fail to identify or incorrectly identify patients as having $\mathrm{FM}^{9}$.

A multidimensional Health Assessment Questionnaire (MDHAQ) has been found informative in most rheumatic diseases studied ${ }^{10}$, based on a RAPID3 (Routine Assessment of Patient Index Data 3 - an index within the MDHAQ). Additional MDHAQ scales have been reported to provide clues to FM, including a high pain score relative to physical function score ${ }^{11}$ and a high number of positive responses on a symptom checklist ${ }^{12}$.

This study examines an additional feature of the MDHAQ to provide clues to the presence of comorbid FM, without the need for administration of a separate, condition-specific FM questionnaire, recognizing that a clinical FM diagnosis requires the judgment of a clinician to synthesize all available information about a patient.

\section{MATERIALS AND METHODS}

Patients. All patients with all diagnoses at Liverpool Hospital, Australia, complete an MDHAQ at all visits before seeing the rheumatologist. The treating clinician assigns 1 or more diagnoses at the first and subsequent patient visits. Most of the patients included in this study (79\%) had their first clinic visit and diagnosis(es) assigned prior to the study onset. All clinical diagnoses and all MDHAQ data are included in a database. All data were exported for analyses to STATA 12.0 for Mac (StataCorp LP).

Patients seen between February 2013 and August 2016 by KAG at a weekly clinic also completed a $2011 \mathrm{FM}$ criteria questionnaire at the same time as the MDHAQ questionnaire to compare with candidate FM Assessment Screening Tool (FAST) indices. Patients included in the study were older than 18 years, had a primary diagnosis of any rheumatic condition except FM, and had complete MDHAQ and 2011 FM criteria cross-sectional data at a random visit during the study period. The primary diagnosis was assigned by the treating physician, who did not examine the 2011 FM criteria results when each diagnosis was assigned. Approval by the district Human Research and Ethics Committee was obtained for this study (LNR/13/LPOOL/370 Local project number 13/229LNR). All patients consent to the use of their anonymized data for research purposes, including publication.

Design of MDHAQ. The MDHAQ (Figure 1) is designed for use in routine care with a primary purpose to improve the quality of clinical care and patient outcomes ${ }^{13}$. It includes 10 queries concerning activities of daily living to evaluate physical function (FN) and $3(0-10)$ visual numerical scales (VNS) for pain, patient's global assessment (PtGA), and fatigue. RAPID3 is a composite index that includes the 3 rheumatoid arthritis (RA) core dataset measures, FN, pain, and PtGA, each scored 0-10 for a total of $0-30$. MDHAQ/RAPID3 has been found informative in osteoarthritis (OA), systemic lupus erythematosus (SLE), ankylosing spondylitis (AS), psoriatic arthritis (PsA), vasculitis, gout, and FM, in addition to RA ${ }^{10,12,14-20}$.

The MDHAQ also includes 3 queries to rate how difficult it was to "get a good night's sleep" (sleep quality), to "deal with feelings of anxiety or being nervous" (anxiety), and to "deal with feelings of depression or feeling blue" (depression) in the traditional, patient-friendly HAQ format ${ }^{21}$. A self-report RA Disease Activity Index (RADAI) painful joint count is recorded ${ }^{22}$ on the MDHAQ. The RADAI queries patients to score pain in 16 specific joint groups, 8 each on the right and left sides: fingers, wrists, elbows, shoulders, hips, knees, ankles, and toes. Scoring options are 0 (none), 1 (mild), 2 (moderate), or 3 (severe) pain; total scores range from 0 to 48 . RADAI selfreport joint counts have been shown to be useful in patients with different rheumatic diseases ${ }^{23}$. In addition, the MDHAQ includes a 60-symptom checklist $^{12}$ and recent medical history information ${ }^{24}$. Demographic data include sex, date of birth, ethnicity, and years of formal education ${ }^{25}$.

2011 FM criteria. The 2011 FM criteria ${ }^{8}$ were developed as a patient self-report questionnaire for epidemiologic and clinical studies, and consist of 2 scales: the Widespread Pain Index (WPI) and the symptom severity scale (SSS). The WPI component queries patients to indicate whether they have had pain or tenderness over the previous week in specific joints and areas, including the shoulder girdle, hip, jaw, upper back, lower back, upper arm, upper leg, chest, neck, abdomen, lower arm, and lower leg. Patients grade the right and left side of the body separately from 0 or 1 with a maximum total score of 19 . The SSS queries patients to indicate the severity of 6 symptoms over the previous week. Three symptoms [fatigue, trouble thinking or remembering, and waking up tired (unrefreshed)] are scored 0-3: 0 , no problem; 1 , slight or mild problems, generally mild or intermittent; 2 , moderate, considerable problems, often present and/or at a moderate level; and 3 , severe, continuous, life-disturbing problems. The other 3 symptoms [pain or cramps in the lower abdomen, depression, or headache during the previous 6 months] are scored $0-1$ ( 0 No, 1 Yes). When summed, the 6 items result in a total score between 0 and 12 . A patient meets $2011 \mathrm{FM}$ criteria if the following conditions are met: WPI $\geq 7$ and SSS $\geq 5$ or WPI between 3-6 and SSS $\geq 9$, symptoms have been present at a similar level for at least 3 months, and the patient does not have a disorder that would otherwise sufficiently explain the pain. These criteria are used in our study as the reference standard against which the proposed MDHAQ/FAST indices are compared.

FAST indices based on MDHAQ scores. FAST composite cumulative indices were developed from MDHAQ candidate measures, including FN, pain visual analog scale (VAS), PtGA VAS, RAPID3, sleep quality, anxiety, depression, fatigue VAS, RADAI painful joint count, and a 60-symptom checklist. Receiver-operating characteristic (ROC) curves were constructed to recognize those that provided the highest area under the curve (AUC) compared to the 2011 FM criteria as the reference standard (Figure 2). ROC curves were computed for RAPID3 and PtGA, but these variables were not regarded as candidates for FAST indices because they appeared clinically more likely to be associated with somatic symptoms that could be observed by a clinician, such as dyspnea or joint swelling, and were not included in the 2011 FM criteria. The cutpoint for each score to be included in a FAST cumulative index was selected on the basis of the best tradeoff values between sensitivity and specificity on the ROC curve. An optimal cutpoint was identified for each measure on the basis of the ROC curve for that measure.

Statistical analysis. The proportions of patients who met 2011 FM criteria or a clinical diagnosis of FM [assigned by the treating rheumatologist (KAG)] were calculated. Means and SD of demographic measures and clinical characteristics in patients who did and did not meet FM by criteria were compared using $t$ tests, and percentages using chi-square tests.

FAST3 and FAST4 composite cumulative indices were constructed from the optimal cutpoints of the candidate MDHAQ measures with the highest AUC under the ROC curves as described above. Agreement of FAST indices with the 2011 FM criteria as the reference standard was analyzed using the $\kappa$ statistic ${ }^{26}$ and ROC curves (of the indices) for AUC.

\section{RESULTS}

Patient characteristics. The study included 148 patients: 55 (37\%) with RA, 21 (14\%) with OA, 14 (10\%) with PsA, and the remaining 58 (39\%) with other rheumatologic diagnoses (Table 1). Among these patients, $24 \%$ with RA, $38 \%$ with OA, and $21 \%$ with PsA met 2011 criteria, while $22 \%, 38 \%$ and $29 \%$, respectively, had a clinical diagnosis of comorbid FM. There were $13 \%, 29 \%$, and $14 \%$, respectively, who both met 2011 FM criteria and had a clinical diagnosis of FM (Table 1). Among all patients, $29(20 \%)$ met the $2011 \mathrm{FM}$ criteria, $31(21 \%)$ were assigned a clinical diagnosis of FM, $18(12 \%)$ had both a clinical diagnosis and met criteria, while $106(72 \%)$ met neither a clinical diagnosis nor FM criteria (Table 1). Agreement between clinical and 2011 FM criteria was moderate $(83.8 \%, \kappa 0.50, \mathrm{p}<0.001)$. 


\section{Multi-Dimensional Health Assessment Questionnaire (MDHAQ ${ }^{\mathrm{TM}}$ )(R873AU-NP2E)}

This questionnaire includes information not available from blood tests, $X$-rays, or any source other than you. Please try to answer each question, even if you do not think it is related to you at this time. Try to complete as much as you can yourself, but if you need help, please ask. There are no right or wrong answers. Please answer exactly as you think or feel. Thank you.

1. Please tick $(\sqrt{ })$ the ONE best answer for your abilities at this time:

\begin{tabular}{lcccc}
\hline OVER THE PAST WEEK, were you able to: & $\begin{array}{c}\text { Without } \\
\text { ANY } \\
\text { difficulty }\end{array}$ & $\begin{array}{c}\text { With } \\
\text { SOME } \\
\text { difficulty }\end{array}$ & $\begin{array}{c}\text { With } \\
\text { MUCH }\end{array}$ & $\begin{array}{c}\text { UNABLE } \\
\text { to do }\end{array}$ \\
\hline a. Dress yourself, including tying shoelaces and doing buttons? & $\square 0$ & $\square 1$ & $\square 2$ & $\square 3$ \\
\hline b. Get in and out of bed? & $\square 0$ & $\square 1$ & $\square 2$ & $\square 3$ \\
\hline c. Lift a full cup or glass to your mouth? & $\square 0$ & $\square 1$ & $\square 2$ & $\square 3$ \\
\hline d. Walk outdoors on flat ground? & $\square 0$ & $\square 1$ & $\square 2$ & $\square 3$ \\
\hline e. Wash and dry your entire body? & $\square 0$ & $\square 1$ & $\square 2$ & $\square 3$ \\
\hline f. Bend down to pick up clothing from the floor? & $\square 0$ & $\square 1$ & $\square 2$ & $\square 3$ \\
\hline g. Turn regular taps on and off? & $\square 0$ & $\square 1$ & $\square 2$ & $\square 3$ \\
\hline h. Get in and out of a car, bus, train, or airplane? & $\square 0$ & $\square 1$ & $\square 2$ & $\square 3$ \\
\hline i. Walk 3 kilometers, if you wish? & $\square 0$ & $\square 1$ & $\square 2$ & $\square 3$ \\
\hline j. Participate in recreational activities and sports as you wish? & $\square 0$ & $\square 1$ & $\square 2$ & $\square 3$ \\
\hline k. Get a good night's sleep? & $\square 0$ & $\square 1.1$ & $\square 2.2$ & $\square 3.3$ \\
\hline l. Deal with feelings of anxiety or being nervous? & $\square 0$ & $\square 1.1$ & $\square 2.2$ & $\square 3.3$ \\
\hline m. Deal with feelings of depression or feeling down? & $\square 0$ & $\square 1.1$ & $\square 2.2$ & $\square 3.3$ \\
\hline
\end{tabular}

2. How much pain have you had because of your condition OVER THE PAST WEEK? Please indicate below how severe your pain has been:



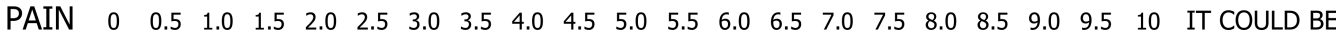

\begin{tabular}{|c|c|c|c|c|c|c|c|c|c|}
\hline \multicolumn{10}{|c|}{$\begin{array}{l}\text { 3. Please tick }(\sqrt{ }) \text { the appropriate spot to indicate the amount of pain } \\
\text { you are having today in each of the joint areas listed below: }\end{array}$} \\
\hline a. LEFT FINGERS & $\square$ & c & $\square 2$ & $\square$ & 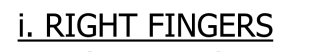 & 0 & $\square 1$ & $\square 2$ & $\square 3$ \\
\hline b. LEFT WRIST & $\bar{\square}$ & & & & & & 1 & & $\square 3$ \\
\hline c. LEFT ELBOW & $\square 0$ & & $\square$ & $\square$ & k. & & $\square 1$ & ப & $\square 3$ \\
\hline d. LEFT SHOULDER & $\square 0$ & [ & $\square 2$ & $\square 3$ & JLDER & $\square 0$ & $\square 1$ & $\square 2$ & $\square 3$ \\
\hline e. LEFT H. & $\square$ & [ & $\square$ & $\square$ & & $\square 0$ & $\square 1$ & $\square$ & $\square 3$ \\
\hline f. $L$ & $\square 0$ & $\square$ & $\square$ & $\square$ & $F$ & $\square 0$ & $\square 1$ & $\square$ & $\square 3$ \\
\hline KLE & $\square 0$ & $\square$ & $\square$ & $\square$ & LEE & $\square 0$ & $\square 1$ & $\square 2$ & $\square 3$ \\
\hline & $\square 0$ & $\square$ & $\square$ & $\square$ & & $\square 0$ & $\square 1$ & $\square 2$ & $\square 3$ \\
\hline q. NECK & $\square 0$ & $\square 1$ & $\square 2$ & $\square 3$ & r. BACK & $\square 0$ & $\square 1$ & $\square 2$ & $\square 3$ \\
\hline
\end{tabular}

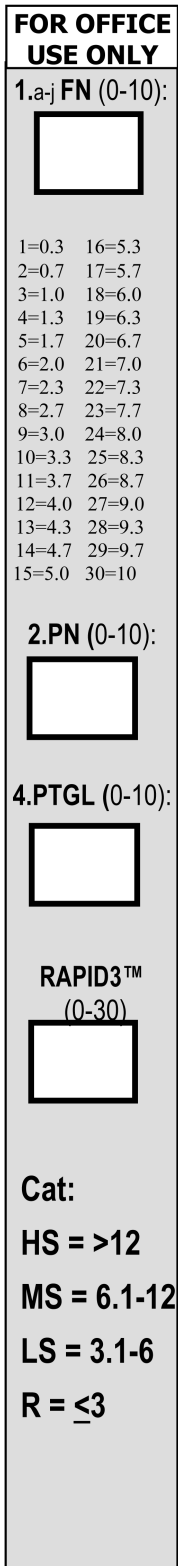

4. Considering all the ways in which illness and health conditions may affect you at this time, please indicate below how you are doing:

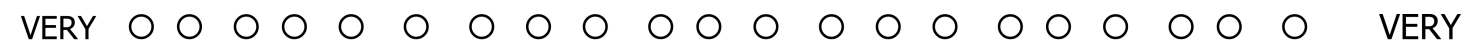
$\begin{array}{lllllllllllllllllllllllll}\text { WELL } & 0 & 0.5 & 1.0 & 1.5 & 2.0 & 2.5 & 3.0 & 3.5 & 4.0 & 4.5 & 5.0 & 5.5 & 6.0 & 6.5 & 7.0 & 7.5 & 8.0 & 8.5 & 9.0 & 9.5 & 10 & \text { POORLY }\end{array}$

\section{Page 1 of 2 [R873AU-NP2R] \\ PLEASE TURN TO THE NEXT PAGE}

Copyright: Health Report Services, Telephone 615-479-

5303, E-mail tedpincus@gmail.com

Figure 1. The form for the multidimensional Health Assessment Questionnaire. Copyright: Health Report Services. Used with permission. 


\section{Please tick $(\sqrt{ })$ if you have experienced any of the following over the lastmonth:}

Fever

Weight gain ( $>5 \mathrm{~kg}$ )

Weight loss (>5 kg)

Feeling sickly

Headaches

Unusual fatigue

Swollen glands

Loss of appetite

Skin rash or hives

_Unusual bruising or bleeding

Other skin problems

_Loss of hair

Dry eyes

_Other eye problems

- Problems with hearing

_Ringing in the ears

Stuffy nose

_ Sores in the mouth

-Dry mouth

_Problems with smell or taste
Lump in your throat

Cough

— Shortness of breath

-Wheezing

Pain in the chest

_ Heart pounding (palpitations)

_Trouble swallowing

- Heartburn or stomach gas

Stomach pain or cramps

_Nausea

_ Vomiting

_Constipation

_Diarrhea

_-Dark or bloody stools

Problems with urination

_ Gynecological (female) problems

Dizziness

_Losing your balance

- Muscle pain, aches, or cramps

_Muscle weakness
Paralysis of arms or legs

_Numbness or tingling of arms or legs

Fainting spells

— Swelling of hands

Swelling of ankles

_ Swelling in other joints

Joint pain

_Back pain

Neck pain

_ Use of drugs not sold in stores

_ Smoking cigarettes

_ More than 2 alcoholic drinks per day

Depression - feeling blue

- Anxiety - feeling nervous

Problems with thinking

_Problems with memory

_ Problems with sleeping

— Sexual problems

_-Burning in sex organs

_Problems with social activities

Please tick $(\sqrt{ })$ here if you have had none of the above over the last month:

6. When you awakened in the morning OVER THE LAST WEEK, did you feel stiff? $\square$ No $\square$ Yes If "No," please go to Item 7. If "Yes," please indicate the number of minutes or hours until you are as limber as you will be for the day.

7. How do you feel TODAY compared to ONE WEEK AGO? Please tick $(\checkmark)$ only one.

Much Better $\square$ (1), Better $\square$ (2), the Same $\square$ (3), Worse $\square$ (4), Much Worse $\square$ (5) than one week ago

8. How often do you exercise aerobically (sweating, increased heart rate, shortness of breath) for at least one-half hour (30 minutes)? Please tick $(\checkmark)$ only one.

$\square 3$ or more times a week (3) $\square 1-2$ times per month (1)

$\square$ 1-2 times per week (2) $\square$ Do not exercise regularly (0) $\square$ Cannot exercise due to disability/ handicap (9)

9. How much of a problem has UNUSUAL fatigue or tiredness been for you OVER THE PAST WEEK?

FATIGUE IS 00000000000000000000000000000 FATIGUE IS A $\begin{array}{lllllllllllllllllllllll}\text { NO PROBLEM } & 0 & 0.5 & 1.0 & 1.5 & 2.0 & 2.5 & 3.0 & 3.5 & 4.0 & 4.5 & 5.0 & 5.5 & 6.0 & 6.5 & 7.0 & 7.5 & 8.0 & 8.5 & 9.0 & 9.5 & 10 & \text { MAJOR PROBLEM }\end{array}$

10. Over the last 6 months have you had: [Please tick $(\sqrt{ })$ ]

$\square$ No $\square$ Yes An operation or new illness

$\square$ No $\square$ Yes Change(s) of arthritis or other medication

$\square$ No $\square$ Yes Medical emergency or stay overnight in hospital

$\square$ No $\square$ Yes Change(s) of address

$\square$ No $\square$ Yes A fall, broken bone, or other accident or trauma

$\square$ No $\square$ Yes Change(s) of marital status

$\square$ No $\square$ Yes An important new symptom or medical problem

$\square$ No $\square$ Yes Change job or work duties, quit work, retired

$\square$ No $\square$ Yes Side effect(s) of any medication or drug

$\square$ No $\square$ Yes Change of medical insurance, Medicare, etc.

$\square$ No $\square$ Yes Smoke cigarettes regularly

$\square$ No $\square$ Yes Change of primary care or other doctor

Please explain any "Yes" answer below, or indicate any other health matter that affects you:

SEX: $\square$ Female, $\square$ Male ETHNIC GROUP: $\square$ Asian, $\square$ Black, $\square$ Hispanic, $\square$ White, $\square$ Other MARITAL STATUS: $\square$ Single $\square$ Married $\square$ Divorced $\square$ Widowed $\square$ Separated

Your Occupation

Work Status: $\square$ Full-time, $\square$ Part-time, $\square$ Disabled

$\square$ Homemaker, $\square$ Self-Employed, $\square$ Retired,

$\square$ Seeking work, $\square$ Other
Please circle the number of years of education you have completed:

$$
\begin{array}{llllllllllll}
1 & 2 & 3 & 4 & 5 & 6 & 7 & 8 & 9 & 10 & 11 & 12 \\
13 & 14 & 15 & 16 & 17 & 18 & 19 & 20 & \text { more than } 20
\end{array}
$$

Please write your weight:__ $\mathbf{c m}$

Your Name

Date of Birth Today's Date

Page 2 of 2 Thank you for completing this questionnaire to help keep track of your medical care. Copyright: Health Report Services, Telephone 615-479-5303, E-mail tedpincus@gmail.com

R873AU2R

Figure 1. Continued.

Personal non-commercial use only. The Journal of Rheumatology Copyright @ 2020 . All rights reserved. 

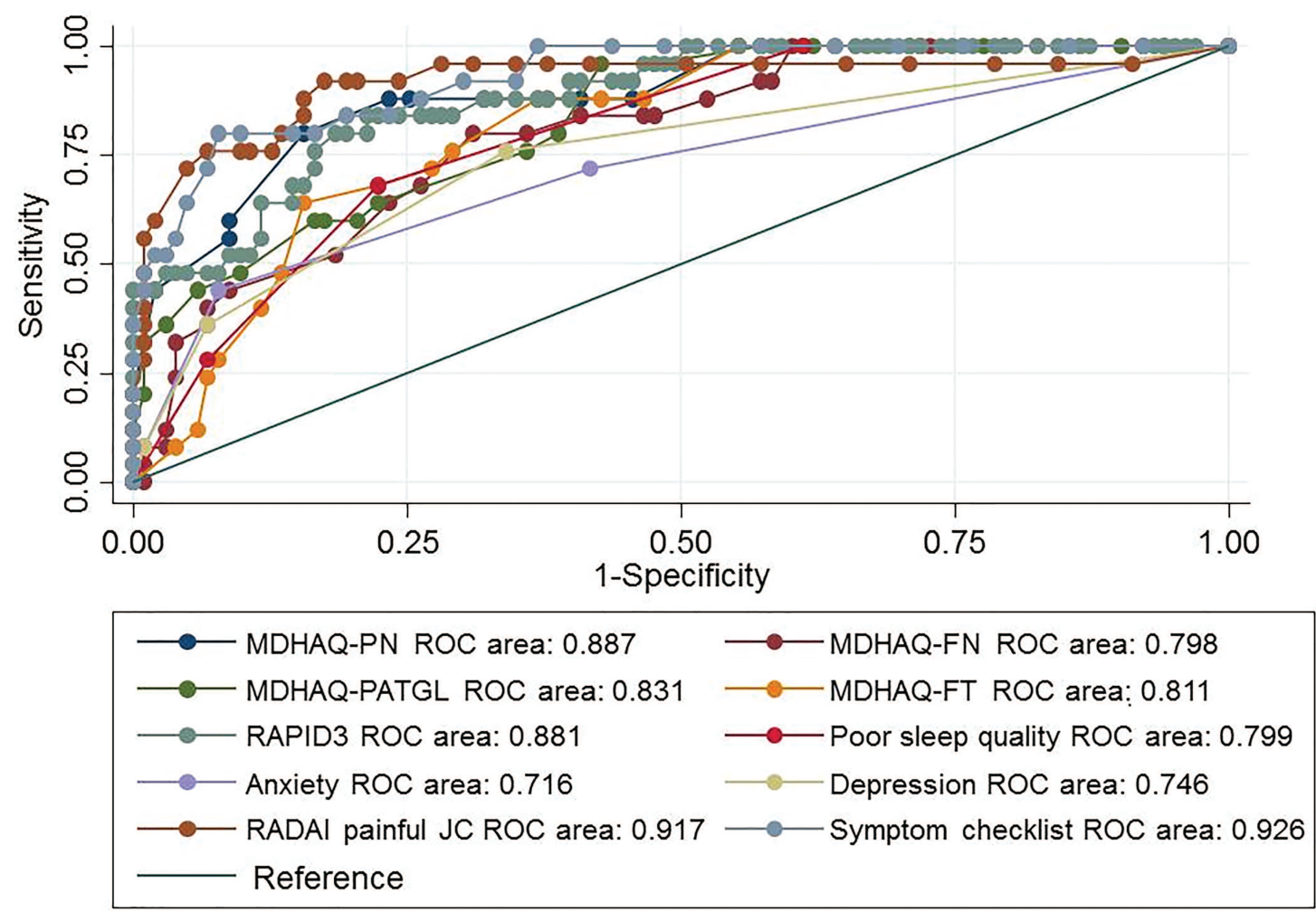

Figure 2. Receiver-operating characteristic (ROC) curve analysis of multidimensional Health Assessment Questionnaire (MDHAQ) variables versus 2011 FM criteria. FM: fibromyalgia; PN: pain; PATGL: patient's global assessment; RAPID3: Routine Assessment of Patient Index Data; RADAI: Rheumatoid Arthritis Disease Activity Index; JC: joint count; FN: function; FT: fatigue.

Table 1. Proportion of patients with different diseases meeting 2011 FM criteria and/or a clinical diagnosis of FM.

\begin{tabular}{|c|c|c|c|c|c|c|c|}
\hline Diagnosis & Total & $\begin{array}{l}2011 \text { FM Criteria } \\
\text { Positive }\end{array}$ & $\begin{array}{l}\text { Total Clinical } \\
\text { FM Diagnosis }\end{array}$ & $\begin{array}{c}\text { Both Meet } 2011 \\
\text { FM Criteria, and FM } \\
\text { Diagnosis Positive }\end{array}$ & $\begin{array}{l}\text { Only } 2011 \text { FM } \\
\text { Criteria Positive }\end{array}$ & $\begin{array}{l}\text { Only Clinical FM } \\
\text { Diagnosis Positive }\end{array}$ & $\begin{array}{c}\text { Neither Meet } 2011 \\
\text { FM Criteria nor } \\
\text { FM Diagnosis }\end{array}$ \\
\hline RA & 55 & $13(24)$ & $12(22)$ & $7(13)$ & $6(11)$ & $5(9)$ & $37(67)$ \\
\hline $\mathrm{OA}$ & 21 & $8(38)$ & $8(38)$ & $6(29)$ & $2(10)$ & $2(10)$ & $11(52)$ \\
\hline PsA & 14 & $3(21)$ & $4(29)$ & $2(14)$ & $1(7)$ & $2(14)$ & $9(43)$ \\
\hline Other diagnoses & 58 & $5(9)$ & $7(12)$ & $3(5)$ & $2(3)$ & $4(7)$ & $49(85)$ \\
\hline Total & 148 & $29(20)$ & $31(21)$ & $18(12)$ & $11(7)$ & $13(9)$ & $106(72)$ \\
\hline
\end{tabular}

Except for totals, data are n (\%). FM: fibromyalgia; RA: rheumatoid arthritis; OA: osteoarthritis; PsA: psoriatic arthritis.

The majority of patients $(80.4 \%)$ was female and white $(68 \%)$ or Asian (12\%). No statistically significant differences were seen in ethnicity or education level between those who did or did not meet 2011 FM criteria in this study (Table 2). Comparison of MDHAQ scores with 2011 FM criteria. Patients who met 2011 FM criteria had significantly poorer scores on all MDHAQ scales, including for physical function, pain VAS, patient global VAS, self-report joint counts, symptom checklist, and fatigue VAS, compared to patients who did not meet criteria ( $p<0.001$; Table 2$)$. ROC analyses indicated that the highest AUC values were seen for symptom checklist (0.926), self-report joint count (RADAI; 0.917),
RAPID3 (0.881), pain VAS (0.887), PtGA (0.831), and fatigue VAS (0.811). Lower AUC versus the $2011 \mathrm{FM}$ criteria (range 0.716-0.799) were seen for remaining MDHAQ scores including physical function, anxiety, depression, and sleep quality (Figure 2). These variables were not analyzed further despite being significantly different from scores in people with no FM, to develop an optimal, feasible index for clinical settings. PtGA and RAPID3 were not regarded as candidates for FAST indices.

The optimal cutpoints were $\geq 16$ for symptom checklist and self-report painful joint count and $\geq 6$ for pain and fatigue VAS. FAST3 cumulative indices include a cumulative score

\section{Personal non-commercial use only. The Journal of Rheumatology Copyright $\odot$ 2020. All rights reserved}


Table 2. Characteristics of patients according to 2011 FM criteria.

\begin{tabular}{|c|c|c|c|c|}
\hline \multirow[t]{2}{*}{ Characteristics } & \multirow[b]{2}{*}{ Total, $\mathrm{n}=148$} & \multicolumn{2}{|c|}{ FM } & \multirow[b]{2}{*}{$\mathrm{p}$} \\
\hline & & $\begin{array}{l}2011 \text { FM Criteria Positive, } \\
\text { n }=29\end{array}$ & $\begin{array}{l}2011 \text { FM Criteria Negative, } \\
\qquad \mathrm{n}=119\end{array}$ & \\
\hline Female, n (\%) & $119(80.4)$ & $24(82.8)$ & $89(74.8)$ & 0.36 \\
\hline \multicolumn{5}{|l|}{ Ethnicity, n (\%) } \\
\hline White & $100(68)$ & $22(75.9)$ & $78(65.5)$ & 0.51 \\
\hline Hispanic & $7(5)$ & $2(7)$ & $5(4)$ & \\
\hline Others & $22(15)$ & $4(14)$ & $18(15)$ & \\
\hline Formal education & $11.8(4.1)$ & $12.0(3.8)$ & $11.8(4.2)$ & 0.83 \\
\hline MDHAQ Function $(0-10)$, mean $( \pm \mathrm{SD})$ & $2.4(2.1)$ & $4.2(1.9)$ & $2.0(1.9)$ & $<0.0001$ \\
\hline MDHAQ Pain $(0-10)$, mean $( \pm$ SD) & $4.4(2.9)$ & $7.6(2.3)$ & $3.6(2.5)$ & $<0.0001$ \\
\hline MDHAQ Global $(0-10)$, mean $( \pm$ SD) & $4.3(2.8)$ & $7.1(2.4)$ & $3.7(2.5)$ & $<0.0001$ \\
\hline Clinical FM+, n $(\%)$ & $31(21)$ & $18(62)$ & $13(11)$ & $<0.001$ \\
\hline Clinical FM-, n (\%) & $117(79)$ & $11(34)$ & $106(89)$ & \\
\hline
\end{tabular}

FM: fibromyalgia; MDHAQ: multidimensional Health Assessment Questionnaire; RAPID3: Routine Assessment of Patient Index Data 3; RADAI: Rheumatoid Arthritis Disease Activity Index.

of the symptom checklist, painful joint count, and either a pain VAS called FAST3-P, or fatigue VAS called FAST3-F. A FAST4 cumulative index includes a cumulative score of the symptom checklist, painful joint count, and both pain and fatigue VAS (Figure 1).

FAST3-P of $\geq 2$ correctly classified $90.9 \%$ of patients versus $2011 \mathrm{FM}$ criteria, with a sensitivity of $81.5 \%$ and a specificity of $93.3 \%$ (Table 3 ). FAST3-F $\geq 2$ correctly classified $89.4 \%$ of patients versus $2011 \mathrm{FM}$ criteria, with a sensitivity of $77.8 \%$ and a specificity of $92.4 \%$ (Table 3 ). FAST $4 \geq 3$ correctly classified $91.7 \%$ of patients versus 2011 FM criteria, with a sensitivity of $70.4 \%$ and a specificity of 97.1\% (Table 3).

Agreement with a clinical diagnosis of FM was $81.1 \%$ for FAST3-P, $85.6 \%$ for FAST3-F, and 58.8\% for FAST4 (Table $4)$. The $\kappa$ values for FAST3-P, FAST3-F, and FAST4 versus

Table 3. Sensitivity and specificity of MDHAQ measures and FAST indices versus 2011 FM criteria.

\begin{tabular}{lcccc}
\hline Variables & Cutoff Point & Sensitivity, $\%$ & Specificity, $\%$ & Correctly Classified, $\%$ \\
\hline Individual items on MDHAQ & & & & \\
Symptom checklist, $\mathrm{n}=148$ & $\geq 16$ & 79.3 & 84.9 & 83.8 \\
RADAI, $\mathrm{n}=132$ & $\geq 16$ & 74.1 & 87.6 & 84.8 \\
MDHAQ-Pain, $\mathrm{n}=148$ & $\geq 6$ & 86.2 & 73.9 & 76.3 \\
MDHAQ-Fatigue, $\mathrm{n}=148$ & $\geq 6$ & 75.8 & 75.6 & 75.7 \\
FAST3-P (0-3) & $\geq 1$ & 96.3 & 70.5 & 90.9 \\
& $\geq 2$ & 81.5 & 93.3 & 90.1 \\
FAST3-F (0-3) & 3 & 43.9 & 90.7 & 72.0 \\
& $\geq 1$ & 96.3 & 65.7 & 89.4 \\
FAST4 (0-4) & $\geq 2$ & 77.8 & 92.4 & 89.4 \\
& 3 & 51.8 & 99.1 & 86.7 \\
& $\geq 1$ & 96.3 & 59.1 & 91.7 \\
\hline
\end{tabular}

MDHAQ: multidimensional Health Assessment Questionnaire; FM: fibromyalgia; FAST: FM Assessment Screening Tool; RADAI: Rheumatoid Arthritis Disease Activity Index self-report painful joint count; FAST3-P: FAST cumulative score of pain, self-report painful joint count, and symptom checklist; FAST3-F: FAST cumulative score of fatigue, self-report painful joint count, and symptom checklist; FAST4: FAST cumulative score of pain, fatigue, self-report painful joint count, and symptom checklist. 
2011 criteria were $0.73,0.68$, and 0.72 , respectively, and versus the clinical diagnosis were $0.44,0.57$, and 0.51 , respectively (Table 4).

\section{DISCUSSION}

We found that FAST indices based on MDHAQ scales provide clues to the presence of FM in patients with other rheumatic diseases compared to the 2011 FM criteria as the reference standard, against which the proposed FAST criteria were examined in this study. The 2011 FM criteria are designated in the report title as "for clinical and epidemiological studies," but also may provide clues to the diagnosis of FM in the clinic. The total 2011 FM criteria score derived from this questionnaire as a continuous variable also provides information regarding the degree of "fibromyalgianess" that patients experience ${ }^{27}$.

The 2011 report indicated that $21.1 \%$ of patients with RA, $16.8 \%$ with OA, and $36.7 \%$ with SLE met the revised FM criteria $^{8}$. The symptom severity burden is similar in patients with other rheumatic diagnoses, and it has been suggested that a distinction between "primary" and "secondary" FM is not needed ${ }^{28}$. This recommendation supports use of these criteria to classify patients who have other rheumatic diagnoses and FM in the current report.

Agreement between the $2011 \mathrm{FM}$ criteria and the clinical diagnosis of FM in this study was moderate $(83.8 \%, \kappa 0.50$, $\mathrm{p}<0.001)$, a level somewhat higher than reported in another study $(79.2 \%, \kappa 0.41)^{9}$. It is noteworthy that about $25 \%$ of previously diagnosed patients with FM did not satisfy the ACR 1990 classification criteria at the time of the 2010 study $^{7}$, and the modified ACR 2010 criteria were satisfied by $60 \%$ with a prior diagnosis of FM in the 2011 study $^{8}$. These minor differences reflect differences between the clinicians, patients, and clinical environments in these studies, but general agreement in the range of $70-85 \%$ has been found.
One advantage of using the MDHAQ to identify FM is that it has been found informative in all rheumatic diseases studied ${ }^{10}$. It is not feasible in most busy clinical settings to add administration of another questionnaire, such as an additional FM-specific questionnaire. In addition, the FAST3 and FAST4 scores are easily calculated directly from the MDHAQ during the consultation.

Previous reports have identified clues to diagnosis and characterization of FM exclusively by self-report on the Fibromyalgia Impact Questionnaire ${ }^{29}$ and MDHAQ ${ }^{11,12}$. FAST3 and FAST4 indices provide relatively high sensitivity and specificity for alerting the clinician to a possible diagnosis of FM compared to the 2011 FM criteria. An additional report from Rush University supports the use of MDHAQ indices to provide clues to the diagnosis of $\mathrm{FM}^{30}$.

This study has a number of limitations. First, it is a crosssectional study and patient symptoms may fluctuate over time; further longitudinal data may help to recognize the possible stability or sensitivity to change of the FAST indices, as well as whether a particular FAST3 or FAST4 may perform substantially better than others. Second, dichotomous criteria for the presence or absence of FM may obscure FM as a "spectrum" disorder of "fibromyalgianess"27, although cutpoints may serve as convenient "anchors" for many continuous variables, including laboratory tests such as erythrocyte sedimentation rate, serum glucose, etc. Third, this study does not use the 2016 modification of the FM criteria $^{31}$, which was reported after commencement of this study, although no patients in the study had regional pain syndromes; therefore, it appears unlikely the modifications would have meaningfully changed the results. Fourth, FAST3 and FAST4 scores misclassify some patients according to the 2011 criteria; and further investigation in larger populations of patients with rheumatic disease is required.

It is not suggested that FAST indices are in any way a substitute for a careful evaluation to determine whether a

Table 4. Classification of FM according to FAST3-P, FAST3-F, and FAST4 compared to $2011 \mathrm{FM}$ criteria and clinical diagnosis ( $\mathrm{n}=132)$.

\begin{tabular}{|c|c|c|c|c|}
\hline $\mathrm{N}=132$ & Criteria Positive & Criteria Negative & Criteria Positive & Criteria Negative \\
\hline FAST3-P-positive FM & $22(81.5 \%)$ & $7(6.7 \%)$ & $16(57.1 \%)$ & $13(12.5 \%)$ \\
\hline FAST3-P-negative FM & \multicolumn{2}{|c|}{ Correct: $90.9 \%, \kappa 0.73$} & \multicolumn{2}{|c|}{ Correct: $81.1 \%, \kappa 0.44$} \\
\hline FAST3-F-positive FM & $21(77.8 \%)$ & $8(7.6 \%)$ & $19(67.9 \%)$ & $10(9.6 \%)$ \\
\hline FAST4-positive FM & $19(70.4 \%)$ & $3(2.9 \%)$ & $14(50 \%)$ & $8(7.7 \%)$ \\
\hline \multirow[t]{2}{*}{ FAST4-negative FM } & $8(29.6 \%)$ & $102(97.1 \%)$ & $14(50 \%)$ & $96(92.3 \%)$ \\
\hline & \multicolumn{2}{|c|}{ Correct: $91.7 \%, \kappa 0.72$} & \multicolumn{2}{|c|}{ Correct: $83.3 \%, \kappa 0.51$} \\
\hline
\end{tabular}

FM: fibromyalgia; FAST3-P: Fibromyalgia Assessment Screening Tools cumulative score of pain, self-report painful joint count, and symptom checklist; FAST3-F: FAST cumulative score of fatigue, self-report painful joint count, and symptom checklist; FAST4: FAST cumulative score of pain, fatigue, self-report painful joint count, and symptom checklist.

Personal non-commercial use only. The Journal of Rheumatology Copyright $\subset$ 2020. All rights reserved. 
patient has FM, or that there may not exist other reasons for certain patients to meet cutpoint values for FAST3 and FAST4. A definitive diagnosis of FM requires a careful history and examination of the patient, and interpretation of laboratory tests and other ancillary data. Nevertheless, it may be of considerable value to assess the presence of FM in patients with other rheumatic diseases using quantitative criteria from the 2011 FM questionnaire or the FAST indices to assist clinicians in recognizing this frequent diagnosis.

We have developed simple FAST cumulative, composite indices that provide clues to the presence of FM in patients with primary diagnoses of other rheumatic diseases. These indices are based entirely on the patient self-report MDHAQ questionnaire, which is used in routine care in the setting of the research and other rheumatology settings, and does not require a disease-specific FM questionnaire. FAST3 provides greater sensitivity but lower specificity than FAST4 for clues to FM; it may be desirable to use a FAST3-P index as the first screening tool for greater sensitivity, and check positive patients according to FAST4 for greater specificity. The FAST indices can be incorporated easily into routine care and may assist clinicians to identify patients with FM in the context of other comorbid rheumatic diseases. They remain a tool to support clinical judgment and are not a substitute for appropriate and thorough clinical history, physical examination, and comprehensive patient assessment for a diagnosis of FM.

\section{REFERENCES}

1. Queiroz LP. Worldwide epidemiology of fibromyalgia. Curr Pain Headache Rep 2013;17:356.

2. Wolfe F, Cathey MA, Kleinheksel SM. Fibrositis (fibromyalgia) in rheumatoid arthritis. J Rheumatol 1984;11:814-8.

3. Thune PO. The prevalence of fibromyalgia among patients with psoriasis. Acta Derm Venereol 2005;85:33-7.

4. De Marco G, Cattaneo A, Battafarano N, Lubrano E, Carrera CG, Marchesoni A. Not simply a matter of psoriatic arthritis: epidemiology of rheumatic diseases in psoriatic patients. Arch Dermatol Res 2012;304:719-26.

5. Wolfe F, Brahler E, Hinz A, Hauser W. Fibromyalgia prevalence, somatic symptom reporting, and the dimensionality of polysymptomatic distress: results from a survey of the general population. Arthritis Care Res 2013;65:777-85.

6. Wolfe F, Smythe HA, Yunus MB, Bennett RM, Bombardier C, Goldenberg DL, et al. The American College of Rheumatology 1990 Criteria for the Classification of Fibromyalgia. Report of the Multicenter Criteria Committee. Arthritis Rheum 1990;33:160-72.

7. Wolfe F, Clauw DJ, Fitzcharles MA, Goldenberg DL, Katz RS, Mease P, et al. The American College of Rheumatology preliminary diagnostic criteria for fibromyalgia and measurement of symptom severity. Arthritis Care Res 2010;62:600-10.

8. Wolfe F, Clauw DJ, Fitzcharles MA, Goldenberg DL, Hauser W, Katz RS, et al. Fibromyalgia criteria and severity scales for clinical and epidemiological studies: a modification of the ACR preliminary diagnostic criteria for fibromyalgia. J Rheumatol 2011;38:1113-22.

9. Wolfe F, Schmukler J, Jamal S, Castrejon I, Gibson KA, Srinivasan $\mathrm{S}$, et al. Diagnosis of fibromyalgia: disagreement between fibromyalgia criteria and clinician-based fibromyalgia diagnosis in a university clinic. Arthritis Care Res 2019;71:343-51.
10. Castrejon I. The use of MDHAQ/RAPID3 in different rheumatic diseases a review of the literature. Bull Hosp Jt Dis (2013) 2017;75:93-100

11. Callahan LF, Pincus T. A clue from a self-report questionnaire to distinguish rheumatoid arthritis from noninflammatory diffuse musculoskeletal pain. The P-VAS:D-ADL ratio. Arthritis Rheum 1990;33:1317-22.

12. DeWalt DA, Reed GW, Pincus T. Further clues to recognition of patients with fibromyalgia from a simple 2-page patient Multidimensional Health Assessment Questionnaire (MDHAQ). Clin Exp Rheumatol 2004;22:453-61.

13. Pincus T, Maclean R, Yazici Y, Harrington JT. Quantitative measurement of patient status in the regular care of patients with rheumatic diseases over 25 years as a continuous quality improvement activity, rather than traditional research. Clin Exp Rheumatol 2007;25:69-81.

14. Pincus T. Can RAPID3, an index without formal joint counts or laboratory tests, serve to guide rheumatologists in tight control of rheumatoid arthritis in usual clinical care? Bull NYU Hosp Jt Dis 2009;67:254-66.

15. Pincus T, Mandelin AM 2nd, Swearingen CJ. Flowsheets that include MDHAQ physical function, pain, global, and RAPID3 scores, laboratory tests, and medications to monitor patients with all rheumatic diseases: an electronic database for an electronic medical record. Rheum Dis Clin North Am 2009;35:829-42, x-xi.

16. Askanase AD, Castrejon I, Pincus T. Quantitative data for care of patients with systemic lupus erythematosus in usual clinical settings: a patient multidimensional health assessment questionnaire and physician estimate of noninflammatory symptoms. J Rheumatol 2011;38:1309-16.

17. Castrejon I, Bergman MJ, Pincus T. MDHAQ/RAPID3 to recognize improvement over 2 months in usual care of patients with osteoarthritis, systemic lupus erythematosus, spondyloarthropathy, and gout, as well as rheumatoid arthritis. J Clin Rheumatol 2013;19:169-74.

18. Danve A, Reddy A, Vakil-Gilani K, Garg N, Dinno A, Deodhar A. Routine assessment of patient index data 3 score (RAPID3) correlates well with Bath Ankylosing Spondylitis Disease Activity Index (BASDAI) in the assessment of disease activity and monitoring progression of axial spondyloarthritis. Clin Rheumatol 2015;34:117-24.

19. Annapureddy N, Elsallabi O, Baker J, Sreih AG. Patient-reported outcomes in ANCA-associated vasculitis. A comparison between Birmingham Vasculitis Activity Score and Routine Assessment Of Patient Index Data 3. Clin Rheumatol 2016;35:395-400.

20. Cinar M, Yilmaz S, Cinar FI, Koca SS, Erdem H, Pay S, et al. A patient-reported outcome measures-based composite index (RAPID3) for the assessment of disease activity in ankylosing spondylitis. Rheumatol Int 2015;35:1575-80.

21. Pincus T, Swearingen C, Wolfe F. Toward a multidimensional health assessment questionnaire (MDHAQ): Assessment of advanced activities of daily living and psychological status in the patient-friendly health assessment questionnaire format. Arthritis Rheum 1999;42:2220-30.

22. Stucki G, Liang MH, Stucki S, Bruhlmann P, Michel BA. A selfadministered rheumatoid arthritis disease activity index (RADAI) for epidemiologic research. Psychometric properties and correlation with parameters of disease activity. Arthritis Rheum 1995;38:795-8.

23. Castrejon I, Yazici Y, Pincus T. Patient self-report RADAI (Rheumatoid Arthritis Disease Activity Index) joint counts on an MDHAQ (Multidimensional Health Assessment Questionnaire) in usual care of consecutive patients with rheumatic diseases other than rheumatoid arthritis. Arthritis Care Res 2013;65:288-93.

24. Pincus T, Swearingen CJ. The HAQ compared with the MDHAQ: "Keep it simple, stupid" (KISS), with feasibility and clinical value

Personal non-commercial use only. The Journal of Rheumatology Copyright @ $\odot 2020$. All rights reserved 
as primary criteria for patient questionnaires in usual clinical care. Rheum Dis Clin North Am 2009;35:787-98, ix.

25. Pincus T, Sokka T, Kautiainen H. Further development of a physical function scale on a MDHAQ [corrected] for standard care of patients with rheumatic diseases. J Rheumatol 2005;32:1432-9.

26. Landis JR, Koch GG. The measurement of observer agreement for categorical data. Biometrics 1977;33:159-74.

27. Wolfe F. Fibromyalgianess. Arthritis Rheum 2009;61:715-6.

28. Wolfe F, Walitt B, Rasker JJ, Hauser W. Primary and secondary fibromyalgia are the same: The universality of polysymptomatic distress. J Rheumatol 2019;46:204-12.
29. Burckhardt CS, Clark SR, Bennett RM. The Fibromyalgia Impact Questionnaire: development and validation. J Rheumatol 1991;18:728-33.

30. Schmukler J, Jamal S, Castrejon I, Block JA, Pincus T. Fibromyalgia Assessment Screening Tools (FAST) based on only Multidimensional Health Assessment Questionnaire (MDHAQ) scores as clues to fibromyalgia. ACR Open Rheumatol 2019; 1:516-25.

31. Wolfe F, Clauw DJ, Fitzcharles MA, Goldenberg DL, Häuser W, Katz RL, et al. 2016 revisions to the 2010/2011 fibromyalgia diagnostic criteria. Semin Arthritis Rheum 2016;46:319-29. 